\title{
Examining the Compassion Status of Healthcare Professionals Working in the Palliative Care Units
}

\author{
(D) Özlem ORUÇ, ${ }^{1}$ (I) Merve HÖRMET IGGDE, ${ }^{4}$ (i) Vildan KOCATEPE, ${ }^{2}$ (D) Dilek YILDIRIM ${ }^{3}$ \\ 'Department of Palliative Care, İstanbul Provincial Health Directorate İstanbul Süreyyapaşa Chest Diseases and Thoracic Surgery \\ Training and Research Hospital, İstanbul-Turkey \\ ${ }^{2}$ Department of Nursing, Acıbadem Mehmet Ali Aydınlar University, School of Health Sciences, İstanbul-Turkey \\ ${ }^{3}$ Department of Nursing, İstanbul Sabahattin Zaim University, School of Health Sciences, İstanbul-Turkey \\ ${ }^{4}$ Department of Chest Diseases, İstanbul Provincial Health Directorate İstanbul Süreyyapaşa Chest Diseases and Thoracic Surgery \\ Training and Research Hospital, İstanbul-Turkey
}

\section{OBJECTIVE}

This study was conducted to examine the compassion status of healthcare professionals working in the palliative care unit.

\section{METHODS}

Sample of the study consisted of 81 healthcare professionals working in three hospitals in Istanbul. The data were collected with "Sociodemographic Characteristics Form" and "Compassion Scale" in January and February 2019.

\section{RESULTS}

In this study, 65 (80.2\%) of the participants were nurses, 12 (14.8\%) were physicians and four (4.9\%) were health staff members. There was a significant difference between the compassion scores (ZMWU=-2.470; $\mathrm{p}=0.014$ ) of the healthcare professionals according to their gender. There was a significant difference between the compassion scores (ZMWU=-2.197; $\mathrm{p}=0.028$ ) of the participants according to their status of having children. There was a significant difference between the compassion scores $(t=4.128 ; \mathrm{p}=0.001)$ of the healthcare professionals according to their perception of interpersonal relations. There was a positively weak correlation between the age averages and total compassion scores $(r=0.253 ; p=0.022)$ of the participants.

\section{CONCLUSION}

There are many factors that may affect the feelings of compassion of healthcare professionals who work in palliative care, especially with patients in the end-of-life period. It is important for healthcare professionals to know these factors that may affect their own sense of compassion and control their negative features.

Keywords: Compassion; nurses; palliative care; physicians.

Copyright $\odot$ 2020, Turkish Society for Radiation Oncology

\section{Introduction}

Palliative care $(\mathrm{PC})$ is a multidisciplinary care approach in which practices about preventing the pain by meeting the physical, social, psychological and spiritual needs of the patients and controlling undesired symptoms are primary. Patients and families are focused in PC rather than lifetime of the patients
Dr. Vildan KOCATEPE

Acıbadem Mehmet Ali Aydınlar Üniversitesi,

Sağlık Bilimleri Fakültesi,

Hemşirelik Bölümü,

İstanbul-Turkey

E-mail:vildan.kocatepe@acibadem.edu.tr 
to enhance the quality of life.[1,2] End-of-life care is based on the understanding that death is a part of normal life in the PC requires the integration of different aspects of care. [3,4] Compassion, which is shown as the cornerstone of quality healthcare services by patients, families, clinicians and politicians, is the basis of end-of-life care.[3,5] The sensitivity of patients and their dependence on healthcare professionals bring a moral responsibility to healthcare professionals, and this obligation allows the adoption of the concept of compassion. [3,6]

Compassion is described as sadness and pity felt against a bad situation faced by an individual or another creature.[7] Compassion in the PC includes spending time with the patients, empathising, listening and respecting patients, and helping patients to manage the hospital setting. [3,5] While there are studies on compassion fatigue of healthcare professionals, nurses and nursing students providing care to different patients in the literature, to our knowledge, no study was found in the field of PC, which is the unit requiring the most distinctive reflection of compassion feeling. Only a single study was conducted on how patients perceived the compassion status of healthcare professionals in the PC clinics. In this study, it was reported that the patients explained the compassion understanding as commitment, readiness, sincerity, respect and helpfulness. In the same study, patients asked healthcare professionals to communicate with patients, to speak with a language that they could understand, to respect the patients and to show interest. $[5,8]$

This study was conducted to investigate the compassion status of healthcare professionals working in the palliative care unit.

\section{Materials and Methods}

\section{Population and Sample of the Study}

The population of this study was composed of all healthcare professionals working in two training and research hospitals and in a state hospital located in Istanbul city. The sample consisted of 81 healthcare professionals who met the inclusion criteria and were voluntary to participate in this study from the population.

\section{The Inclusion Criteria}

- Working in the palliative care unit for at least one month,

- Agreeing to participate in this study

\section{The Exclusion Criteria}

- Changing the service during the study period,

- Being on leave during the study period.

\section{Type, Time and Place of this Study}

This descriptive study was conducted in palliative care units of two training and research hospitals and a state hospital in Istanbul. The data were collected between January and February 2019.

\section{Data Collection Tools}

The data of this study were collected using "Sociodemographic Characteristics Form" and "Compassion Scale". Data collection forms were filled out by healthcare professionals.

\section{Sociodemographic Characteristics Form}

"Sociodemographic Characteristics Form" having 15 questions, including six open-ended questions about sociodemographic characteristics, was prepared by the researchers.

\section{Compassion Scale}

Turkish validity and reliability study of the Compassion Scale, which was developed by Pommier, was conducted by Akdeniz and Deniz.[9,10] The scale consists of a total of 24 items. The scores are rated with a fivepoint Likert type. The scale questions six subscales, including kindness (items of 6, 8, 16,24), indifference (items of 2,12,14,18), common humanity (items of $11,15,17,20$ ), separation(items of $3,5,10,22$ ), mindfulness (items of $4,9,13,21$ ) and disengagement (items of $1,7,19,23)$. Indifference, separation and disengagement subscales of the scale are reversely scored. The scores obtained using this method were calculated, and the total mean score was obtained. As the total score obtained from the scale increases, the level of compassion increases.

\section{Data Assessment}

In the data assessment, descriptive statistics were conducted with mean and standard deviation; whereas the comparison studies were conducted using the MannWhitney U test, Kruskal Wallis test, T-test, and Pearson's Correlation Test.

\section{Ethical Considerations}

To conduct this study, written ethics committee approval (2019-2/16) was obtained from Acrbadem University and Acıbadem Health Institutions Medical Research Ethics Committee. Informed consent was ob- 
tained from the healthcare professionals constituting the sample of this study in accordance with the voluntariness principle.

\section{Results}

Out of the participants, $65(80.2 \%)$ were nurses, 12 (14.8\%) were physicians, and four (4.9\%) were health officers. The mean age of the physicians participating in this study was $38.83 \pm 11.71$, the mean of the nurses was $26.41 \pm 4.59$, and the mean age of the health officers was $25.75 \pm 3.09 .58(71.6 \%)$ of the participants were female, and $58(71.6 \%)$ were married.

The total compassion score of the healthcare professionals was $3.71 \pm 0.31$. Total compassion scores were minimum of 2.83 and maximum of 4.25 (Table 1 ).

There was a significant difference between the compassions scores of the healthcare professionals by gender $(Z M W U=-2.470 ; \mathrm{p}=0.014)$, kindness subscale scores (ZMWU $=-2.788 ; \mathrm{p}=0.005)$ and separation subscale scores (ZMWU $=-2.473 ; \mathrm{p}=0.013$ ). There was a significant difference between the compassion scores (ZMWU $=-2.197 ; \mathrm{p}=0.028$ ); kindness subscale scores (ZMWU $=-2.467 ; \mathrm{p}=0.014$ ) and mindfulness subscale (ZMWU $=-2.664 ; \mathrm{p}=0.008$ ) of the participants in terms of the status of having children. There was a statistically significant difference between the common humanity of the healthcare professionals who received palliative care training and the healthcare professionals who did not $(t=-2.680 ; p=0.009)$. There was a statistically significant difference between the total compassion scores of the healthcare professionals in terms of their perception of their own interpersonal relationships $(\mathrm{t}=4.128$; $\mathrm{p}=0.001$ ). When the subscales were examined, there were significant differences between the kindness $(\mathrm{t}=4,079 ; \mathrm{p}=0.001)$, indifference $(\mathrm{t}=-2.436 ; \mathrm{p}=0.018)$, $\operatorname{separation}(\mathrm{t}=-2.884 ; \mathrm{p}=0.006)$, mindfulness $(\mathrm{t}=4.312$;

\begin{tabular}{lccc} 
Table 1 & \multicolumn{3}{l}{$\begin{array}{l}\text { Compassion scores of healthcare professionals } \\
(\mathrm{n}=81)\end{array}$} \\
& Min & Max & Mean \pm SD \\
\hline Kindness & 2.50 & 5.00 & $4.08 \pm 0.59$ \\
Indifference & 1.00 & 4.00 & $1.99 \pm 0.66$ \\
Common humanity & 2.50 & 5.00 & $4.16 \pm 0.62$ \\
Separation & 1.00 & 3.75 & $2.07 \pm 65$ \\
Conscious awareness & 2.25 & 5.00 & $4.05 \pm 59$ \\
Disengagement & 1.00 & 4.25 & $2.05 \pm 0.66$ \\
Total & 2.83 & 4.25 & $3.71 \pm 31$ \\
\hline
\end{tabular}

SD: Standart devision $\mathrm{p}=0.001)$ and disengagement $(\mathrm{t}=-2.685 ; \mathrm{p}=0.009)$ scores in terms of perception of interpersonal relationships,. It was observed that there was no significant difference between the compassions scores of the healthcare professionals and their marital status, educational level, profession, the status of preferring the unit they work, and satisfaction with their unit ( $>>0.05)$ (Table 2).

There was a positive weak correlation between the mean age of the participants and the total compassion scores $(r=0.253 ; p=0.022)$ and mindfulness subscale scores $(\mathrm{r}=0.278 ; \mathrm{p}=0.012)$. There was a positive weak correlation between the working time of the participants and their compassion scores $(r=0.298 ; p=0.007)$, common humanity subscale scores $(r=0.246 ; \mathrm{p}=0.027)$ and mindfulness subscale scores $(r=0.276 ; p=0.013)$. There was a positive weak correlation between the weekly working hours of the participants and their common humanity subscale scores $(r=0.309 ; \mathrm{p}=0.005)$ and disengagement subscale scores $(r=0.256 ; p=0.021)$. There was no correlation between the working time of healthcare professionals in the PC and their compassion scores ( $\mathrm{p}>0.05)$ (Table 3$)$.

\section{Discussion}

This study was conducted to investigate the compassion status of the healthcare professionals working in the palliative care unit. It was observed that the compassion mean score of the healthcare professionals was $3.71 \pm 0.31$. The compassion level increases as the score obtained from the scale increases. When considering that the highest score to be taken from the scale is 5 , it can be asserted that healthcare professionals working in the palliative care unit have high compassion levels. On the other hand, many personal characteristics of healthcare professionals (marital status, educational status, occupations, status of selecting their unit with their own decision, satisfaction with their unit) did not affect their compassion status. These data suggest that healthcare professionals did not experience burnout and served willingly while serving individuals.

There are a limited number of studies on compassion in healthcare professionals in Turkey and it is observed that these studies have been mostly conducted with nurses.[11-15] Çingöl et al. concluded in their study conducted with 494 nursing students that the compassion scale mean scores of the participants were $4.19 \pm 0.44$ and the compassion levels of the participants were high.[12] Uslu and Buldukoğlu reported in their systematic review prepared about compassion fatigue in psychiatric nurses that compassion satisfaction of 
Table 2 Total compassion and subscale scores in terms of some sociodemographic characteristics

\begin{tabular}{|c|c|c|c|c|c|c|c|c|}
\hline & n (\%) & Kindness & Indifference & $\begin{array}{l}\text { Common } \\
\text { humanity }\end{array}$ & Separation & $\begin{array}{l}\text { Conscious } \\
\text { awareness }\end{array}$ & Disengagemen & Total \\
\hline \multicolumn{9}{|l|}{ Gender } \\
\hline Male & $23(28.4)$ & $3.78 \pm 0.61$ & $2.19 \pm 0.82$ & $4.06 \pm 0.54$ & $2.40 \pm 0.78$ & $3.89 \pm 0.64$ & $2.31 \pm 0.79$ & $3.57 \pm 0.307$ \\
\hline Female & $58(71.6)$ & $4.202 \pm 0.55$ & $1.91 \pm 0.57$ & $4.21 \pm 0.65$ & $1.94 \pm 0.55$ & $4.12 \pm 0.56$ & $1.94 \pm 0.58$ & $3.77 \pm 0.299$ \\
\hline Statistical value ${ }^{\dagger}$ & & -2.788 & -1.289 & -0.962 & -2.473 & -1.544 & -1.920 & -2.470 \\
\hline$p$ & & $0.005^{*}$ & 0.197 & 0.336 & $0.013^{*}$ & 0.123 & 0.055 & $0.014^{*}$ \\
\hline \multicolumn{9}{|l|}{ Marital status } \\
\hline Married & $23(28.4)$ & $4.13 \pm 0.56$ & $1.95 \pm 0.56$ & $4.20 \pm 0.61$ & $1.94 \pm 0.49$ & $4.08 \pm 0.65$ & $1.97 \pm 0.49$ & $3.75 \pm .30$ \\
\hline Single & $58(71.6)$ & $4.06 \pm 0.60$ & $2.01 \pm 0.70$ & $4.15 \pm 0.63$ & $2.12 \pm 0.71$ & $4.04 \pm 0.56$ & $2.08 \pm 0.72$ & $3.70 \pm .31$ \\
\hline Statistical value ${ }^{\dagger}$ & & -0.478 & -0.074 & -0.174 & -0.893 & -0.745 & -0.128 & -0.745 \\
\hline$p$ & & 0.663 & 0.941 & 0.862 & 0.372 & 0.456 & 0.898 & 0.456 \\
\hline \multicolumn{9}{|c|}{ Statuses of having a children } \\
\hline No & $69(85.2)$ & $4.01 \pm 0.60$ & $2.02 \pm .68$ & $4.14 \pm .64$ & $2.12 \pm .68$ & $3.98 \pm 0.59$ & $2.10 \pm 0.68$ & $3.68 \pm 0.32$ \\
\hline Yes & $12(14.8)$ & $4.45 \pm 0.39$ & $1.79 \pm .49$ & $4.29 \pm .55$ & $1.81 \pm .46$ & $4.45 \pm 0.36$ & $1.77 \pm 0.49$ & $3.89 \pm 0.17$ \\
\hline Statistical value ${ }^{\dagger}$ & & -2.467 & -0.845 & -0.517 & -1.576 & -2.664 & -1.262 & -2.197 \\
\hline $\mathrm{p}$ & & $0.014^{*}$ & 0.398 & 0.605 & 0.115 & $0.008^{*}$ & 0.207 & $0.028^{*}$ \\
\hline \multicolumn{9}{|l|}{ Education } \\
\hline High school & $5(6.2)$ & $4.25 \pm 0.75$ & $2.15 \pm 0.28$ & $4.55 \pm 0.44$ & $2.10 \pm 0.80$ & $4.20 \pm 0.32$ & $2.10 \pm 0.67$ & $3.80 \pm 0.27$ \\
\hline Associate's degree & $9(11.1)$ & $4.08 \pm 0.66$ & $2.02 \pm 0.77$ & $4.51 \pm 0.47$ & $2.38 \pm 0.74$ & $3.94 \pm 0.48$ & $2.39 \pm 0.63$ & $3.74 \pm 0.30$ \\
\hline University & 58 (71.6) & $4.05 \pm 0.60$ & $1.97 \pm 0.68$ & $4.04 \pm 0.63$ & $2.04 \pm 0.66$ & $4.01 \pm 0.63$ & $2.01 \pm 0.69$ & $3.68 \pm 0.32$ \\
\hline Graduate & $9(11.1)$ & $4.16 \pm 0.41$ & $2.00 \pm 0.64$ & $4.36 \pm 0.56$ & $1.94 \pm 0.41$ & $4.38 \pm 0.41$ & $2.00 \pm 0.48$ & $3.82 \pm 0.21$ \\
\hline Statistical value & & 0.962 & 1.043 & 7.816 & 2.716 & 3.750 & 1.331 & 1.763 \\
\hline$p$ & & 0.811 & 0.791 & 0.050 & 0.438 & 0.290 & 0.722 & 0.623 \\
\hline \multicolumn{9}{|l|}{ Occupation } \\
\hline Nurse & $65(80.2)$ & $4.09 \pm 0.64$ & $1.99 \pm 0.70$ & $4.12 \pm 0.65$ & $2.10 \pm 0.68$ & $4.01 \pm 0.62$ & $2.03 \pm 0.70$ & $2.69 \pm 0.32$ \\
\hline Physician & $12(14.8)$ & $4.04 \pm 0.29$ & $2.00 \pm 0.56$ & $4.37 \pm 0.48$ & $1.87 \pm 0.50$ & $4.33 \pm 0.43$ & $2.14 \pm 0.47$ & $3.83 \pm 0.24$ \\
\hline Health officer & $4(4.9)$ & $4.06 \pm 0.42$ & $1.93 \pm 0.23$ & $4.25 \pm 0.20$ & $2.18 \pm 0.62$ & $3.87 \pm 0.14$ & $2.12 \pm 0.47$ & $3.69 \pm 0.19$ \\
\hline Statistical value & & 0.317 & 0.064 & 1.481 & 1.190 & 3.888 & 1.825 & 1.955 \\
\hline$p$ & & 0.853 & 0.969 & 0.477 & 0.552 & 0.143 & 0.401 & 0.376 \\
\hline \multicolumn{9}{|l|}{ PC Education } \\
\hline No & $51(63)$ & $4.05 \pm 0.61$ & $2.00 \pm 0.68$ & $4.02 \pm 0.61$ & $2.10 \pm 0.69$ & $4.00 \pm 0.61$ & $2.03 \pm 0.71$ & $3.67 \pm 0.29$ \\
\hline Yes & $30(37)$ & $4.13 \pm 0.56$ & $1.97 \pm 0.63$ & $4.40 \pm 0.59$ & $2.03 \pm 0.59$ & $4.14 \pm 0.55$ & $2.07 \pm 0.58$ & $3.79 \pm 0.33$ \\
\hline Statistical value $\mathrm{e}^{\S}$ & & -0.578 & 0.195 & -2.680 & 0.457 & $0-.968$ & -0.233 & -1.683 \\
\hline$p$ & & 0.565 & 0.846 & $0.009^{*}$ & 0.649 & 0.336 & 0.817 & 0.096 \\
\hline \multicolumn{9}{|c|}{ Preferring the unit they work } \\
\hline No & $48(59.3)$ & $4.06 \pm 0.59$ & $2.01 \pm 0.66$ & $4.23 \pm 0.64$ & $2.11 \pm 0.67$ & $4.03 \pm 0.60$ & $2.13 \pm 0.63$ & $3.72 \pm 0.32$ \\
\hline Yes & $33(40.7)$ & $4.10 \pm 0.59$ & $1.96 \pm 0.69$ & $4.06 \pm 0.58$ & $2.02 \pm 0.64$ & $4.09 \pm 0.58$ & $1.93 \pm 0.70$ & $3.70 \pm 0.29$ \\
\hline Statistical value ${ }^{\S}$ & & -0.284 & 0.355 & 1.181 & 0.614 & -0.500 & 1.275 & 0.249 \\
\hline $\mathrm{p}$ & & 0.777 & 0.723 & 0.241 & 0.541 & 0.619 & 0.206 & 0.804 \\
\hline \multicolumn{9}{|c|}{ Satisfaction with their unit } \\
\hline No & $13(16)$ & $3.88 \pm 0.65$ & $2.21 \pm 0.79$ & $3.88 \pm 0.59$ & $2.11 \pm 0.80$ & $3.71 \pm 0.80$ & $2.21 \pm 0.65$ & $3.56 \pm 0.40$ \\
\hline Yes & $68(84)$ & $4.12 \pm 0.57$ & $1.95 \pm 0.63$ & $4.22 \pm 0.61$ & $2.06 \pm 0.63$ & $4.12 \pm 0.52$ & $2.02 \pm 0.66$ & $3.74 \pm 0.28$ \\
\hline
\end{tabular}


Table 2 Cont.

\begin{tabular}{|c|c|c|c|c|c|c|c|c|}
\hline & $n(\%)$ & Kindness & Indifference & $\begin{array}{l}\text { Common } \\
\text { humanity }\end{array}$ & Separation & $\begin{array}{l}\text { Conscious } \\
\text { awareness }\end{array}$ & Disengagement & Total \\
\hline Statistical value ${ }^{\dagger}$ & & -1.455 & -0.941 & -1.935 & -0.058 & -1.364 & -1.071 & -1.372 \\
\hline$p$ & & 0.146 & 0.347 & 0.053 & 0.953 & 0.173 & 0.284 & 0.170 \\
\hline \multicolumn{9}{|c|}{ Their perception of their own interpersonal relationships } \\
\hline Good & $46(56.8)$ & $4.30 \pm 0.40$ & $1.83 \pm 0.56$ & $4.25 \pm 0.58$ & $1.89 \pm 0.48$ & $4.28 \pm 0.46$ & $1.88 \pm 0.56$ & $3.83 \pm 0.22$ \\
\hline Low & $35(43.2)$ & $3.78 \pm 0.67$ & $2.20 \pm 0.73$ & $4.05 \pm 0.66$ & $2.32 \pm 0.77$ & $3.76 \pm 0.61$ & $2.27 \pm 0.72$ & $3.55 \pm 0.34$ \\
\hline Statistical value & & 4.079 & -2.436 & 1.479 & -2.884 & 4.312 & -2.685 & 4.128 \\
\hline$p$ & & $0.001^{*}$ & $0.018^{*}$ & 0.143 & $0.006^{*}$ & $0.001^{*}$ & $0.009^{*}$ & $0.001^{*}$ \\
\hline
\end{tabular}

${ }^{*} \mathrm{p}<0.05 ;{ }^{\dagger}$ Mann Whitney $\mathrm{U}$ test was used; ${ }^{*}$ Kruskal-Wallis test was used; ${ }^{5} \mathrm{~T}$ test was used

Table 3 The correlation between compassion total score and subscales with mean age and working characteristics

\begin{tabular}{lccccccc} 
& Kindness & Indifference & $\begin{array}{c}\text { Common } \\
\text { humanity }\end{array}$ & Separation & $\begin{array}{c}\text { Conscious } \\
\text { awareness }\end{array}$ & Disengagement & Total \\
\hline Age average & & & & & & & \\
Statistical value & 0.134 & -0.179 & 0.150 & -0.104 & 0.278 & -0.076 & 0.253 \\
p & 0.234 & 0.110 & 0.181 & 0.354 & $0.012^{*}$ & 0.501 & $0.022^{*}$ \\
Occupational years & & & & & & & \\
Statistical value & 0.133 & -0.167 & 0.246 & -0.115 & 0.276 & -0.038 & 0.298 \\
p & 0.236 & 0.135 & $0.027^{*}$ & 0.306 & $0.013^{*}$ & 0.738 & $0.007^{*}$ \\
PC working year & & & & & & & -0.069 \\
Statistical value & -0.107 & 0.029 & 0.056 & 0.111 & -0.054 & 0.036 & 0.540 \\
p & 0.341 & 0.795 & 0.617 & 0.323 & 0.630 & 0.748 & \\
Weekly working hours & & & & & & & 0.133 \\
Statistical value & -0.105 & 0.208 & 0.309 & -0.002 & 0.053 & 0.256 & 0.133 \\
p & 0.897 & 0.062 & $0.005^{*}$ & 0.984 & 0.637 & $0.021^{*}$ & 0.236 \\
\hline
\end{tabular}

${ }^{*} p<0.05$; Pearson Correlation is used

psychiatric nurses was low and their compassion fatigue and burnout levels were high.[14] In another study, it was reported that nurses generally experienced compassion fatigue in the intensive care unit and they preferred the strategy of being isolated from the intensive care mentally and physically in and outside of the workplace.[11] In a study conducted to determine the compassion fatigue in physicians interested in head and neck surgery, it was stated that compassion levels of the physicians were high. Thus, they experienced compassion fatigue.[16]

In the study, it was seen that the compassion levels of women were significantly higher than men. In various studies, it has been stated that compassion levels of women were expected to be higher.[17-19] In another study, compassion fatigue in 346 healthcare professionals, including 159 physicians and 187 nurses, was reported to be seen higher in female nurses.[13] It can be thought that this result is because women are more sensitive, loving and maternal and integrate this situation in all aspects of life. In addition, it was observed in this study that compassion levels of the healthcare professionals who had children were higher than the healthcare professionals without any children. This result was thought to arise from that the majority of the group was female, and the healthcare professionals who were parents displayed more empathy and compassion behaviours. 
During the PC training, the meaning of PC and the patients' expectations are emphasized. $[8,20,21]$ Healthcare professionals who are aware of the needs and expectations of their patients are expected to have higher rates of communication and other sharing with patients than other professionals. As a result of this study, a higher rate of the common humanity of the healthcare professionals who received PC training supports this situation.

An important result obtained from the present study was that compassion levels and most of the subscales of healthcare professionals who were good at perceiving interpersonal relationships were significantly higher than the healthcare professionals who had moderate and low perception. Compassion fatigue prevention strategies are versatile. The healthcare team can support their social care and spiritual self-care with professionally supportive interpersonal relationships. $[8,22]$ Based on this point of view, it is an expected result that the healthcare professionals working in the $\mathrm{PC}$ who are good at perceiving interpersonal relations have high compassion levels.

As the mean age and the working duration in the profession of healthcare professionals working in the PC increase, total compassion levels, common humanity and mindfulness subscale mean scores are also seen to increase. This result can be interpreted that the PC team can evaluate the diagnosis and treatment results better as they gain more experience, and they can develop better empathy by feeling the problems experienced by a person with a chronic illness or a person who is about to die. In addition, as the professional experience of the PC team increases, the time they spend on the learning period decreases and they can make more room for their patients in their emotional worlds. Another study also supports this result. $[8,16]$

It was observed that as the working hours of the PC team increases regardless of being nurse, physician or health officer, their status of cutting their communications with the patient increased. When combined with another result, it can be considered that as healthcare professionals are more aware of the shares, they behave more recessive in communicating with the patient. It can be thought that healthcare professionals who work with terminally ill patients and the healthcare professionals who lost patients with whom they spend a lot of time together have the tendencies to reduce their communication with patients to protect themselves psychologically.

\section{Conclusion}

This study showed that the healthcare professionals working in the PC did not have compassion fatigue. Compassion fatigue can be seen in the PC team dealing with the treatment of patients who are in the last period of life, have chronic diseases, have unchanging physiological results. Particularly, personal and professional characteristics of healthcare professionals working with patients who are at the end of life affect compassion emotions. It is important for healthcare professionals to know these factors that may affect their compassion emotions and to control their characteristics negative affecting their compassion emotions.

Peer-review: Externally peer-reviewed.

Conflict of Interest: There is no conflict of interest.

Ethics Committee Approval: To conduct this study, written ethics committee approval (2019-2/16) was obtained from Acıbadem University and Acıbadem Health Institutions Medical Research Ethics Committee.

Financial Support: There is no financial sport.

Authorship contributions: Concept - Ö.O., M.H.İ., V.K., D.Y.; Design - Ö.O., M.H.İ., V.K., D.Y.; Supervision - Ö.O.; Funding - None; Materials - Ö.O., M.H.I., V.K., D.Y.; Data collection and/or processing - Ö.O., M.H.I..; Data analysis and/or interpretation - V.K., D.Y.; Literature search - V.K., D.Y.; Writing - Ö.O., M.H.I.., V.K., D.Y.; Critical review Ö.O., M.H.I.., V.K., D.Y.

\section{References}

1. Best M, Butow P, Olver I. Do patients want doctors to talk about spirituality? A systematic literature review. Patient Educ Couns 2015;98(11):1320-8.

2. Fadıloğlu Ç. Palyatif Bakım Semptom Yönetimi ve Yaşam Sonu Bakımı. In: Yıldırım Y, Fadıloğlu Ç, editors. Palyatif Bakım. Ankara: Nobel Tip Kitabevi; 2017. p. 1-3.

3. Sinclair S, Norris JM, McConnell SJ, Chochinov HM, Hack TF, Hagen NA, et al. Compassion: a scoping review of the healthcare literature. BMC Palliat Care 2016;15:6.

4. Madenoğlu Kıvanç M. Türkiyedde Palyatif Bakım Hizmetleri. HSP 2017:4(2):132-5.

5. Fernando A, Rea C, Malpas PJ. Compassion from a palliative care perspective. N Z Med J 2018;131(1468):2532.

6. Hem $\mathrm{MH}$, Heggen $\mathrm{K}$. Is compassion essential to nursing practice?. Contemp Nurse 2004;17(1-2):19-31. 
7. Turkish Language Society. (2011). Turkish Dictionary. Ankara, Turkey. Available at: http://www.tdk.gov.tr/ index.php? option $=$ com_gts\&kelime $=$ MERHAMET . Accessed Mar 12, 2020.

8. Taylor EJ, Mamier I, Ricci-Allegra P, Foith J. Self-reported frequency of nurse-provided spiritual care. Appl Nurs Res 2017;35:30-5.

9. Pommier EA. The compassion scale. Dissertation Abstracts International Section A: Humanities and Social Sciences 2011;72:1174.

10. Akdeniz S, Deniz ME. The Turkish adaptation of Compassion Scale: The validity and reliability study. The Journal of Happiness \& Well-Being, 2016;4(1):50-61.

11. Atilla Gök G. Merhamet Etmenin Dayanılmaz Ağırlığı: Hemşirelerde Merhamet Yorgunluğu. Süleyman Demirel University The Journal of Faculty of Economics and Administrative Sciences 2015;20(2):299313.

12. Çingöl N, Çelebi E, Zengin S, Karakaş M. The investigation of compassion level of nursing students in a health college. Klinik Psikiyatri 2018;21:61-7.

13. Polat FN, Erdem R. The relationship between the level of compassion fatigue and quality of professional life: The case of medical professionals. Journal of Süleyman Demirel University Institute of Social Sciences 2017;26:291-312.

14. Uslu E, Buldukoğlu K. Compassion Fatigue in Psychiatric Nursing: A Systematic Review. Current Approaches in Psychiatry 2017;9(4):421-30.
15. Gijsberts MHE, Liefbroer AI, Otten R, Olsman E. Spiritual Care in Palliative Care: A Systematic Review of the Recent European Literature. Med Sci (Basel) 2019;7(2):25.

16. Cingi CC, Eroglu E. Cingi CC, Eroglu E. Compassion fatigue in health care personnel. Osmangazi Journal of Medicine 2019;41(1):58-71.

17. Tatum KJ. Adherence to Gender Roles as a Predictor of compassion and self-compassion in women and men (dissertation). Baylor University: 2012.

18. Salazar LR. The relationship between compassion, interpersonal communication apprehension, narcissism and verbal aggressiveness. The Journal of Happiness \& Well-Being, 2016;4(1):1-14.

19. Chakrabarti B, Baron-Cohen S. Empathizing: neurocognitive developmental mechanisms and individual differences. Prog Brain Res 2006;156:403-17.

20. Delgado-Guay MO. Spirituality and religiosity in supportive and palliative care. Curr Opin Support Palliat Care 2014;8(3):308-13.

21. Land V, Parry R, Pino M, Jenkins L, Feathers L, Faull C. Addressing possible problems with patients' expectations, plans and decisions for the future: One strategy used by experienced clinicians in advance care planning conversations. Patient Educ Couns 2019;102(4):670-9.

22. Dikmen Y, Aydın Y, Tabakoğlu P. Compassion fatigue: A Study of critical care nurses in Turkey. Journal of Human Sciences 2016;13(2):2879-84. 